Cahiers $d u$ MONDE RUSSE

\section{Cahiers du monde russe}

Russie - Empire russe - Union soviétique et États indépendants

$43 / 4 \mid 2002$

Intellectuels et intelligentsia

\title{
Terry Martin, The affirmative action empire
}

\author{
Juliette Cadiot
}

\section{OpenEdition}

Journals

Édition électronique

URL : https://journals.openedition.org/monderusse/4045

DOI : $10.4000 /$ monderusse. 4045

ISSN : $1777-5388$

Éditeur

Éditions de l'EHESS

Édition imprimée

Date de publication : 30 décembre 2002

Pagination : 766-768

ISBN : 2-7132-1796-2

ISSN : $1252-6576$

Référence électronique

Juliette Cadiot, «Terry Martin, The affirmative action empire », Cahiers du monde russe [En ligne], 43/4 | 2002, mis en ligne le 17 juin 2009, consulté le 02 septembre 2022. URL : http://

journals.openedition.org/monderusse/4045; DOI : https://doi.org/10.4000/monderusse.4045

Ce document a été généré automatiquement le 2 septembre 2022

Tous droits réservés 


\title{
Terry Martin, The affirmative action empire
}

\author{
Juliette Cadiot
}

\section{RÉFÉRENCE}

Terry MARTIN, The affirmative action empire. Nations and nationalism in the

Soviet Union, 1923-1939. Ithaca-Londres, Cornell University Press, 2001, 496 p.

1 Ce livre est remarquable à la fois par l'étendue du champ qu'il couvre, la somme d'informations directement issues des archives qu'il contient et par la clarté des thèses qui y sont énoncées. Il constitue l'une des premières grandes sommes en histoire depuis l'ouverture des archives qui vise à requalifier l'expérience étatique soviétique en spécifiant la nature de son modèle d' " empire de discrimination positive ». Terry Martin fait référence explicitement aux politiques contemporaines de soutien aux minorités nationales ayant été victimes de discrimination pour conclure que l'Union soviétique fut le premier État du monde à mener ces politiques. Celles-ci conduisirent à définir les territoires en fonction de leur composition ethnique, à attribuer aux nationaux les postes de pouvoir dans les républiques et à promouvoir les langues et les cultures locales. L'équivalent de l'expression « discrimination positive » fait défaut en français : or c'est elle qui permet à Terry Martin de résumer deux aspects essentiels du projet soviétique, à savoir l'organisation de son caractère multiculturel et une lutte active contre des formes de domination sociale issues de la période impériale. Dans cet ouvrage issu de sa thèse, Terry Martin n'envisage que la politique de promotion des minorités nationales. Il suit la constitution, l'évolution, les contradictions et les ambiguités de la politique des nationalités, du début du régime soviétique jusqu'à la Seconde Guerre mondiale. Loin de traiter cette histoire comme un domaine spécifique et en partie marginal de la politique soviétique, il bénéficie de l'intérêt et des problématiques issus des sciences politiques qui, au regard de la dissolution de l'URSS et de la création de nouveaux États-nations, ont fait de l'aspect multinational de l'Union la clé de sa spécificité. Son projet ne sera cependant pleinement accompli que 
lorsque la dimension sociale de l'« affirmative action empire » sera elle aussi totalement prise en compte.

2 À travers une étude des archives du parti et du gouvernement soviétiques, mais aussi des archives locales, en particulier ukrainiennes, Terry Martin dresse une chronologie précise des changements de la direction soviétique sur la question nationale. Par l'usage de multiples métaphores (« ligne politique douce» ou « ligne politique dure», «principe du Piedmont », « nettoyage ethnique »...), il permet à son lecteur de suivre aisément une histoire compliquée. Enfin, son livre marie différentes formes de récits, allant de la description d'une crise politique à l'usage des statistiques ou à l'exposé de l'application des politiques sur le terrain. Néanmoins cette étude reste dominée par l'histoire politique.

3 Le premier chapitre est une très claire introduction à la théorisation de Terry Martin et aux concepts qu'il utilisera tout au long de son livre. Les chapitres suivants sont les subdivisions de trois parties chronologiques qui permettent de rendre compte du tournant de la politique soviétique des nationalités autour de l'année 1932-1933. Le changement est énorme, mais, comme l'auteur l'affirme, n'implique pas une modification réelle de la conception du national chez les élites dirigeantes, mais plutôt une appréciation politique négative des effets de leur politique de promotion des nationalités dans les années 1920. L'Union soviétique passe donc d'un État qui promeut systématiquement les minorités ethniques en leur attribuant et garantissant territoire, élites et culture autonomes, à un État qui réprime les individus des « nations ennemies » en fonction de leur appartenance nationale; d'un pays qui aide les minorités les plus faibles en nombre et les communautés nationales très locales à un pays qui ne reconnaît plus que les plus nombreuses d'entre elles, les «nationalités titulaires». Enfin, Terry Martin consacre un chapitre à la réévaluation de la place de la Russie à la fin des années 1930.

4 Les thèmes abordés sont multiples, depuis les discussions des bolcheviks sur la place à accorder aux revendications et aux différences nationales dans le nouvel État au rôle de l'Ukraine comme élément impulseur et expérimentateur de la politique des nationalités. Une description minutieuse de la politique de création d'unités territoriales nationales à l'échelle la plus locale (les soviets nationaux), ainsi que les débats sur la création des alphabets et sur la politique de la langue permettent de prendre la mesure du volet utopiste de la première politique des nationalités. Le chapitre consacré au nettoyage ethnique et à la création des « nationalités ennemies » dans les années 1930 nous éclaire sur l'autre versant de la politique de promotion du « nationalo-ethnique».

5 Le paradoxe de l'expérience soviétique ici décrite tient au fait que, bien que ses dirigeants aient partagé une vision des identités nationales comme historiques et contingentes, ils ont fini par mener une politique promouvant une vision primordiale des appartenances nationales, en demandant systématiquement aux individus de se définir nationalement dans les documents administratifs, tout comme en suscitant la création, pour les nationalités titulaires, de discours nationalistes essentialisants, faisant remonter la naissance de ces nations à des temps très anciens. Cet aspect conduit le lecteur à interroger les effets d'une politique de promotion systématique des identités nationales et ethniques comme les conditions de formation de l'idéologie nationaliste. Terry Martin explique ce tournant "primordialiste» par les effets de la politique d'inscription systématique de la nationalité des individus dans les documents administratifs, ou encore fait très rapidement allusion à une tendance naturelle du 
peuple à penser les nations comme primordiales. On ne dispose pas encore d'études suffisamment approfondies pour savoir comment la population soviétique a réagi à l'entreprise de définition systématique des individus en fonction de leur nationalité, alors même que dans certaines régions, comme en Asie centrale, elle ne partait d'aucun sentiment national préexistant. En réalité, la constante politique visant à institutionnaliser les différences nationales supposait le primordialisme, dans les formes qui furent prises en URSS avec la répression et l'inscription sur le passeport de la nationalité d'origine à partir de 1938. Et surtout, la conception chez les élites politiques, et en partie les élites savantes, de la population en termes de groupes formés par des cultures particulières et repérables, en partie aveugles aux histoires individuelles, était en elle-même porteuse d'une tendance à réifier les identités collectives.

$6 \quad$ La diversité des voies par lesquelles le pouvoir bolchevik a tenté d'intégrer la population soviétique à son projet étatique et idéologique est multiple. En faisant relativement peu mention des autres moyens de mobilisation et d'organisation étatiques, Terry Martin rend difficile pour le lecteur l'appréciation de la place du national dans une configuration plus large. Par exemple, la démarcation sur le terrain des frontières ne s'est pas faite uniquement en fonction de critères nationaux mais aussi des intérêts des élites régionales et surtout de considérations générales d'organisation économique. Le travail de l'auteur permet cependant de rendre compte de l'importance du caractère multinational de l'URSS pour comprendre les particularités de son histoire, et de changer ainsi la manière de l'étudier, traditionnellement russo-centrée. Sa lecture est absolument indispensable à une juste réévaluation de l'expérience soviétique dans toutes ses dimensions. Les concepts et métaphores utilisés par l'auteur sont plus ou moins heureux (il est permis d'avoir quelques doutes sur la valeur heuristique d'expressions comme " soft/hard lines »), mais l'expression " empire de discrimination positive", même si elle peut choquer certaines conceptions sensibles aux politiques de terreur menées par l'État bolchevik que Martin décrit, est applicable à une série d'autres perspectives, en particulier sociales, et qualifie bien du moins le premier projet soviétique de lutte contre des formes d'organisation sociale issues de l'empire et l'extrême sensibilité politique aux différences de culture collective. 